\title{
Environmental taxation, tax competition and harmonization
}

\author{
Helmuth Cremer \\ University of Toulouse \\ (IDEI and GREMAQ) \\ Toulouse, France \\ Firouz Gahvari* \\ Department of Economics \\ University of Illinois at Urbana-Champaign \\ Urbana, IL 61801, USA
}

January 2003

*We thank Hormozd Gahvari for help in computations. 


\begin{abstract}
This paper studies the tax competition problem in the presence of a global negative externality. It shows that economic integration causes the firms to adopt the same or less polluting technologies, but it nevertheless increases aggregate emissions and lowers welfare. Second, the paper examines the ramifications of partial tax harmonization policies. It shows that harmonizing commodity taxes above their unrestricted Nash equilibrium value may either increase or lower the equilibrium emission tax. Under the former, firms opt for less polluting technologies, aggregate emissions decrease and welfare improves. On the other hand, if emission tax goes down, firms will choose more polluting technologies, aggregate emissions will increase and welfare deteriorates. Finally, harmonizing the emission tax above its unrestricted Nash equilibrium value, which leads the firms to adopt a less polluting technology, also causes aggregate emissions to decline and overall welfare to increase.
\end{abstract}

JEL classification: H21; H23; H73; H87; F15

Keywords: Environmental taxation; tax competition; partial harmonization; polluting technology, emissions 


\section{Introduction}

A major theme of the tax competition literature, and the earlier fiscal federalism literature on which it is based, has been the potential loss in tax revenues as a result of tax competition. It is generally believed that the integration process will exert a negative influence on the ability of the member countries to generate an "adequate" level of tax revenues to finance their social policies. ${ }^{1}$ This paper takes a fresh look at the tax competition issue, and the effectiveness of partial fiscal coordination policies, in the presence of another source of economic inefficiency in the economy. In particular, we have in mind cases where, because of a global externality problem, resourse allocations are inefficient prior to the economic integration.

The underlying reasons for the "race to the bottom" concern are simple to grasp. International economic integration entails the dismantling of barriers to free movements of people, capital and goods among nations. From the perspective of national governments, this increased mobility may be viewed as an opportunity to move other countries' tax bases into one's own. Each country will then try to compete with the others in order to attract the tax bases that are being made mobile. A simple and effective way to achieve this is by lowering one's tax rates. As countries try to undercut one another's tax rates, it is not difficult to envisage an end result in which the tax rates, and the corresponding levels of government services, will be less than optimal. ${ }^{2}$

Applying the logic of tax competition to polluting activities, it appears natural to expect that tax competition would lead to more pollution. However, this expectation

\footnotetext{
${ }^{1}$ The literature also identifies a counter force in terms of a "tax exporting" effect. However, the more serious concerns have been raised about the prospects of less than optimal expenditures on public goods and redistributive policies in Europe. This is reflected in Sinn's (1994) warning that "In the end, all countries will settle at an equilibrium where only benefit taxes are charged, and no redistribution policies are carried out" (p. 100).

${ }^{2}$ There is also the possibility of "excessive" tax rates due to tax exporting effect. However, it is the less-than-optimal-tax-rates result which has received the greatest share of attention. See, e.g., Sinn (1994), and Edwards and Keen (1996). For recent surveys of the tax competition literature, see Cremer et al. (1996), Wilson (1999), Wellisch (2000), Haufler (2001) and Cremer and Pestieau (2002).
} 
is built on an implicit assumption that governments use the same tax instrument for controlling emissions as for generating tax revenues. When armed with both emission and output taxes, a centralized authority may use output taxes for tax competition, keeping emission taxes for the control of emissions. ${ }^{3}$

Under this circumstance, there is no a priori reason to suspect that tax competition per se should lead to more pollution. It is true that cutting output taxes (to foster tax competition) tends to lower the consumer price of polluting goods, leading to an increase in their consumption and with it the aggregate emission levels as well. It is equally true, however, that increasing emission taxes to combat pollution would push the consumer prices up, curtail consumption and lower aggregate emissions. This ameliorating effect on aggregate emissions is further enhanced if an increase in emission taxes induces the firms to switch to less polluting techniques of production. The final outcome will ultimately depend on the balance of these conflicting forces.

We consider a simple setting with two identical countries whose inhabitants consume two goods: a non-polluting numeraire good and a polluting consumption good. Every consumer has an endowment of the numeraire good, some of which he consumes, spending the rest to purchase the polluting good and to pay taxes. Production technologies are identical in both countries. Pollution $\left(\mathrm{CO}_{2}, \mathrm{SO}_{2}\right.$, etc.) is global and a by-product of production. The polluting good may be produced in different ways. Each procedure entails a different resource cost and a different emission level. ${ }^{4}$ Emissions are beneficial in that a higher level of emission reduces the private (per unit) production costs of polluting goods. That is, the production costs of polluting goods are negatively correlated to their emissions. This is to capture the fact that technologies which cut

\footnotetext{
${ }^{3}$ In a companion paper [Cremer and Gahvari (2002)], we show that such a targeting property depends on whether border taxes are origin- or destination-based. For an analysis of this question within the framework of a closed economy, See Cremer and Gahvari (2001).

${ }^{4}$ This models situations where a polluting good may be produced through different production techniques, or using different polluting inputs where each particular input entails a different emission level. Different abatement techniques also imply that a unit of polluting good is associated with different emission levels.
} 
emissions are more expensive to employ. Firms producing the polluting good operate in a competitive environment. The good is produced by an industry that is comprised of a fixed but sufficiently large number of identical firms. It is produced, for a given unit cost of production, by a linear technology subject to constant returns to scale.

The polluting good is produced and consumed in both countries. Prior to economic integration, there is no trade between the two countries. Upon integration, residents of each country will be able to purchase the polluting good from the foreign as well as the home country. While the physical characteristics of the home- and foreign-produced goods are identical, consumers have a preference for purchasing the home-produced goods. We model this by assuming that consumers experience a certain disutility when they consume one unit of the foreign-produced good. The extent of the disutility differs across consumers. Individuals have otherwise identical quasi-linear preferences.

There are two (distortionary) tax instruments: commodity and emission taxes. These are "origin-based". Thus, each country levies a certain tax on each unit of the (polluting) consumption good that its firms produce and sell (regardless of where the purchasers come from). Second, to combat pollution, the country imposes another tax per unit of emissions on (home) firms. Each country rebates its tax revenues to its residents in a lump-sum fashion.

Within this framework, we characterize the emission tax rates in second-best and closed economies and show that no commodity taxes are chosen in either setup. Further, we show that the firms choose an emission technology which is more polluting than the second best. We also show that aggregate emissions exceed their second-best levels as well. Next, we characterize the Nash equilibrium values of commodity and emission taxes as the economy opens up. We show that the formula for emission tax remains the same in closed and open economies. On the other hand, there will be a subsidy on the commodity tax.

Our other results include the finding that economic integration causes the firms to 
adopt the same or less polluting technologies, but it nevertheless increases aggregate emissions and lowers welfare. We then show that the Nash equilibrium value of the emission tax may either increase or decrease as a result of harmonizing the commodity tax above its unrestricted Nash equilibrium value. If the emission tax increases, firms will adopt less polluting technologies. This in turn leads to a lowering of aggregate emissions and improvement in overall welfare. On the other hand, if emission tax goes down, firms will choose more polluting technologies. Under this circumstance, aggregate emissions will increase and welfare deteriorates. Finally, we consider the harmonization of emission taxes above their unrestricted Nash equilibrium value. This would not only lead the adoption of less polluting technologies, but also to a reduction in aggregate emissions and a rise in overall welfare.

\section{The model}

The residents of two identical countries, $A$ and $B$ consume two goods: a polluting good, $x$, and a nonpolluting numeraire. Every consumer has an endowment of $m$ units of the numeraire good and receives $T_{j}$ in lump-sum rebate from the government of $j$ in which he resides.

The level of pollution is determined by total (worldwide) emissions which are created by the production process. The polluting good is produced from the numeraire according to a linear technology with unit $\operatorname{cost} C\left(e_{i}\right)$, where $e_{i}(i=A, B)$ denotes emission per unit of output in country $i$. The more polluting a technology, the less costly it is to employ. Thus unit cost is a decreasing function of emission $e_{i} \cdot{ }^{5}$ We assume also that $C\left(e_{i}\right)$ is continuously differentiable and convex. All firms operate in a perfectly competitive environment.

\footnotetext{
${ }^{5}$ More precisely the assumptions is that $C^{\prime}()<$.0 for all $e_{i}$ up to some limit $\bar{e}$, and that $C^{\prime}(\bar{e})=0$, $i=A, B$. This models situations where a polluting good may be produced through different production techniques, or using different polluting inputs where each particular input entails a different emission level. Different abatement techniques also imply that a unit of polluting good is associated with different emission levels.
} 
In a closed economy, consumers can buy the polluting good only from domestic producers. Upon integration, the polluting good may be traded. While the domestic and foreign goods are identical in their physical characteristics and in quality, consumers have a preference for the domestic product. This means that if prices are equal, all consumers in a given country buy the domestic product. Individuals, however, differ in their attachment to the home product. Put differently, the price differential required to switch to the foreign product differs across consumers. Individuals are identified by $\theta \in[-1,1]$, with $|\theta|$ determining a consumer's preference for domestic goods. A resident of $B$ is identified by a negative $\theta$, while a positive $\theta$ corresponds to a resident of $A$. Population size in each country is normalized to one and $\theta$ is uniformly distributed.

The utility of a person in $j=A, B$ who purchases the polluting good produced in $i=A, B$ is given by

$$
\left\{\begin{array}{l}
u_{j}^{j}=m-p_{j} x_{j}^{j}+h\left(x_{j}^{j}\right)+T_{j}-\varphi(E), \\
u_{i}^{j}=m-p_{i} x_{i}^{j}+h\left(x_{i}^{j}\right)-\delta|\theta| x_{i}^{j}+T_{j}-\varphi(E), \quad \text { with } j \neq i,
\end{array}\right.
$$

where $x_{i}^{j}$ is consumption of the polluting good at the consumer price of $p_{i}, E$ is the global emission level, and $\delta>0$ is a "dislike index". ${ }^{6}$ Standard assumptions apply to the (continuously differentiable) elements in the utility function: $h^{\prime}()>0,. h^{\prime \prime}()<$. and $\varphi^{\prime}()>0,. \varphi^{\prime \prime}() \geq$.0 .

Utility maximization yields

$$
\left\{\begin{array}{l}
h^{\prime}\left(x_{j}^{j}\right)=p_{j}, \\
h^{\prime}\left(x_{i}^{j}\right)=p_{i}+\delta|\theta|, \quad \text { with } j \neq i .
\end{array}\right.
$$

The right-hand side of these expression reflect the net cost of purchasing one unit of the good. For a resident of $j$ who buys the domestic product, this is simply the consumer price, $p_{j}$. On the other hand, the person who buys the foreign product incurs a net (utility) cost of $p_{i}+\delta|\theta|$. From (2) we obtain the demand for the polluting good as:

\footnotetext{
${ }^{6}$ All taxes are origin-based. Consequently the price does not depend on the location of the buyer.
} 
$x_{j}^{j}=x\left(p_{j}\right)$ and $x_{i}^{j}=x\left(p_{i}+\delta|\theta|\right)$. Substituting in (1) then yields $u_{j}^{j}=u\left(p_{j}, T_{j}, E\right)$ and $u_{i}^{j}=u\left(p_{i}+\delta|\theta|, T_{j}, E\right)$.

Let $\tilde{\theta}$ denote the "marginal" consumer who is indifferent between buying home- or foreign-produced goods. If the marginal consumer is a resident of $A(\tilde{\theta}>0)$, we have $p_{A}=p_{B}+\delta \tilde{\theta}$. Similarly, if $\tilde{\theta}$ is a resident of $B(\tilde{\theta}<0), p_{B}=p_{A}-\delta \tilde{\theta}$. In either case

$$
\tilde{\theta}=\frac{p_{A}-p_{B}}{\delta}
$$

Observe that individuals to the left of $\tilde{\theta}$ buy the from country $B$ while individuals to the right of $\tilde{\theta}$ buy from country $A$.

Production and sale of one unit of the polluting good generate $p_{i}-C\left(e_{i}\right)$ in revenues for the government of $i$. Assuming that governments refund all tax proceedings in a lump-sum way to their residents, we have:

$$
\begin{gathered}
T_{A}\left(p_{A}, e_{A} ; p_{B}\right)= \begin{cases}{\left[p_{A}-C\left(e_{A}\right)\right](1-\tilde{\theta}) x\left(p_{A}\right)} & \text { if } p_{A} \geq p_{B}, \\
{\left[p_{A}-C\left(e_{A}\right)\right]\left[x\left(p_{A}\right)+\int_{\tilde{\theta}}^{0} x\left(p_{A}-\delta \theta\right) d \theta\right]} & \text { if } p_{A}<p_{B} .\end{cases} \\
T_{B}\left(p_{B}, e_{B} ; p_{A}\right)= \begin{cases}{\left[p_{B}-C\left(e_{B}\right)\right]\left[x\left(p_{B}\right)+\int_{0}^{\tilde{\theta}} x\left(p_{B}+\delta \theta\right) d \theta\right]} & \text { if } p_{A} \geq p_{B}, \\
{\left[p_{B}-C\left(e_{B}\right)\right](1+\tilde{\theta}) x\left(p_{B}\right)} & \text { if } p_{A}<p_{B} .\end{cases}
\end{gathered}
$$

Similarly, total pollution, $E$, is given by:

$$
E\left(p_{A}, p_{B}, e_{A}, e_{B}\right)= \begin{cases}e_{B}\left[x\left(p_{B}\right)+\int_{0}^{\tilde{\theta}} x\left(p_{B}+\delta \theta\right) d \theta\right]+e_{A}(1-\tilde{\theta}) x\left(p_{A}\right) & \text { if } p_{A} \geq p_{B} \\ e_{B}(1+\tilde{\theta}) x\left(p_{B}\right)+e_{A}\left[\int_{\tilde{\theta}}^{0} x\left(p_{A}-\delta \theta\right) d \theta+x\left(p_{A}\right)\right] & \text { if } p_{A}<p_{B}\end{cases}
$$

In what follows we are mainly interested in symmetric equilibria with $p_{A}=p_{B}$ and $\tilde{\theta}=0$. From that perspective, it is important to note that $T_{A}, T_{B}$ and $E$ are continuous at this point. Furthermore, one can easily show that these functions are in fact differentiable at $p_{A}=p_{B}$. (See the Appendix). 


\subsection{Taxes, and the price of the polluting good}

Each country has two tax instruments to combat pollution. First, a tax of $\tau_{i}$ on each unit of the polluting good that its firms produce (regardless of the location of the buyer). ${ }^{7}$ Second, a tax of $t_{i}$ per unit of emissions on (home) firms. Given the constant returns to scale assumption, profit maximization is equivalent to maximizing profits per unit of output. Consequently a firm in country $i$ chooses $e_{i}$ to maximize

$$
p_{i}-C\left(e_{i}\right)-t_{i} e_{i}-\tau_{i}
$$

which yields, for $i=A, B$,

$$
-C^{\prime}\left(e_{i}\right)=t_{i}
$$

Equation (7) determines emissions per unit as a function of the emissions tax rate. ${ }^{8}$ Finally, competitive equilibrium requires that the price equals marginal (and average) cost so that

$$
p_{i}=C\left(e_{i}\right)-C^{\prime}\left(e_{i}\right) e_{i}+\tau_{i}
$$

\subsection{Welfare}

Denote utilitarian welfare for country $i$ by $W_{i},(i=A, B)$. The use of a utilitarian measure appears natural in our setting. Given quasi-linear preferences this simply corresponds to total surplus. Define $U_{i}($.$) and F($.$) by$

$$
\begin{aligned}
U_{i}\left(p_{i}, T_{i}, E\right) & \equiv \int_{0}^{1}\left[m+h\left(x\left(p_{i}\right)\right)-p_{i} x\left(p_{i}\right)+T_{i}-\varphi(E)\right] d \theta, \\
& =m+h\left(x\left(p_{i}\right)\right)-p_{i} x\left(p_{i}\right)+T_{i}-\varphi(E), \quad i=A, B . \\
\frac{1}{\delta} F(p+\delta \theta) & \equiv \int[h(x(p+\delta \theta))-(p+\delta \theta) x(p+\delta \theta)] d \theta .
\end{aligned}
$$

\footnotetext{
${ }^{7}$ Recall that the tax is origin based.

${ }^{8}$ The second-order condition $C^{\prime \prime}\left(e_{i}\right)>0$ is satisfied from the convexity of $C($.$) .$
} 
We prove in the Appendix that $W_{A}$ and $W_{B}$ have the following characterizations and that they are continuously differentiable everywhere.

$$
\begin{aligned}
& W_{A}= \begin{cases}U_{A}-\tilde{\theta}\left[h\left(x\left(p_{A}\right)\right)-p_{A} x\left(p_{A}\right)\right]+\frac{1}{\delta}\left[F\left(p_{A}\right)-F\left(p_{B}\right)\right] & \text { if } p_{A} \geq p_{B}, \\
U_{A} & \text { if } p_{A}<p_{B} .\end{cases} \\
& W_{B}= \begin{cases}U_{B} & \text { if } p_{A} \geq p_{B}, \\
U_{B}+\tilde{\theta}\left[h\left(x\left(p_{B}\right)\right)-p_{B} x\left(p_{B}\right)\right]-\frac{1}{\delta}\left[F\left(p_{A}\right)-F\left(p_{B}\right)\right] & \text { if } p_{A}<p_{B} .\end{cases}
\end{aligned}
$$

where $T_{i}$ and $E$ are given by equations (4)-(5) and (6).

Note that the middle expression in the right-hand side of (11) [when $p_{A} \geq p_{B}$, ] measures the consumer surplus that country $A$ does not get because some of its residents do not buy the home-produced good. These are the people with a $\theta \in[0, \tilde{\theta})$. Instead, by buying from $B$, these individuals attain a surplus given by the last expression in the right-hand side. The same interpretation applies to (12) and residents of $B$.

\section{$2.3 \quad$ First-best benchmark}

The first-best (utilitarian) solution is obtained by maximizing worldwide welfare, i.e., the sum of utilities of both countries' residents. Given symmetry, one can determine the first-best benchmark by assuming that the two countries cooperate fully in their fiscal policies. That is, they set $\tau_{i}$ and $t_{i}$ taking the welfare of the citizen of both countries into account. Denote the welfare of country $i(i=A, B)$ at a symmetric allocation by $W_{i}^{S}$. From (11) or (12), this is given by

$$
W_{i}^{S}\left(p_{i}, T_{i}, E\right)=m-p_{i} x\left(p_{i}\right)+h\left(x\left(p_{i}\right)\right)+T_{i}-\varphi(E) .
$$

Similarly, country $i$ 's budget constraint at a symmetric allocation is obtained from (4) or (5) and requires

$$
T_{i}=\left[p_{i}-C\left(e_{i}\right)\right] x\left(p_{i}\right) .
$$

The first-best solution is obtained by maximizing $W_{i}^{S}$ subject to (14) and

$$
E=2 e_{i} x\left(p_{i}\right)
$$

We prove in the Appendix that 
Proposition 1 The first-best (utilitarian) allocation, and the supporting prices and tax instruments, are characterized by equations (2), (7), (8), (14), (15), and

$$
\begin{aligned}
\tau_{i} & =0, \\
t_{i} & =-C^{\prime}\left(e_{i}\right)=2 \varphi^{\prime}(E) .
\end{aligned}
$$

\section{Closed borders}

We now study the Nash equilibrium when the borders are closed. Governments choose the values of their fiscal instruments (which determine their emission levels) simultaneously and non-cooperatively. A government's objective function is the welfare of its own residents. Consequently, it does not account for the impact of domestic emission on residents of foreign countries. This indicates that the problem facing each country is not the same as the "first-best benchmark" problem studied earlier.

Without trade, everyone buys the domestic good and we have $\tilde{\theta}=0$. Consequently, the government budget constraint continues to be given by equation (14). Turning to the expression for aggregate emissions, it is given by

$$
E=e_{A} x\left(p_{A}\right)+e_{B} x\left(p_{B}\right)
$$

This is obtained from (6) by setting $\tilde{\theta}$ equal to zero.

The best reply of government $i$ is determined by maximizing $U_{i}$, as specified in equation (9), with respect to $\tau_{i}$ and $t_{i}$, subject to (14) and (18). Solving the problem, setting $\tau_{A}=\tau_{B}$ and $t_{A}=t_{B}$ yields the symmetric Nash equilibrium. We have

Proposition 2 (i) The symmetric Nash equilibrium in a closed economy is characterized (for $i=A, B$ ) by equations (2), (7), (8), (14), (18), and

$$
\begin{aligned}
\tau_{i} & =0, \\
t_{i} & =-C^{\prime}\left(e_{i}\right)=\varphi^{\prime}(E) .
\end{aligned}
$$


(ii) Per-unit emissions are higher than in the first best so that more polluting technologies are adopted.

(iii) Worldwide emissions exceed their first-best levels.

Condition (19) shows that the equilibrium solution for $\tau_{i}$ is equal to its second-best value of zero. This should not be surprising. With closed borders, there is no tax competition between the countries. Hence the optimal tax rule for setting $\tau_{i}$ remains unaffected. On the other hand, the rule for setting emission taxes now differs from the first-best benchmark case. Condition $-C^{\prime}\left(e_{i}\right)=\varphi^{\prime}(E)$ in (20) replaces condition $-C^{\prime}\left(e_{i}\right)=2 \varphi^{\prime}(E)$ of the first-best. Thus, the environmental tax is set at one half the full marginal social damage of emissions. This reflects our earlier observation that each country, when determining its emissions policy, considers the damage to its own citizens only. Part (ii) follows intuitively from this last observation and the fact that $C($.$) and$ $\varphi($.) are convex. Part (iii) is ensured by the fact that the price of the polluting good increases and its consumption declines; see the Appendix.

\section{Open borders}

We now turn to the general specification of the model with the possibility of buying foreign-made products. Trade has important implications for a country's potential tax revenues. With open borders, some residents of one country may find it advantageous to buy from the other country. Consequently, the tax bases of the different countries becomes "more elastic". With closed borders, a change in the tax policy (and the induced price variation) affects the demand (taxable transaction) of a given set of taxpayers. With open borders, this may also affect the number of effective taxpayers in the country. Put differently, tax revenues are affected at the extensive as well as at the intensive margin. Formally, the extensive margin is reflected by variations in $\tilde{\theta}$, the index of the marginal consumer; see Section 2. This changes the nature of the strategic 
interaction between the countries. In addition to the global pollution aspect, there is now a potential for tax competition as well.

We determine the symmetric Nash equilibrium of this redefined game. The strategic variables continue to be the tax rates $t_{i}, \tau_{i}$ which are set simultaneously with each government maximizing welfare of its residents. ¿From the problem of country $i$, we determine its best-reply functions. Setting $\tau_{A}=\tau_{B}$ and $t_{A}=t_{B}$ then yields the symmetric Nash equilibrium. We have

Proposition 3 Denote the absolute value of the elasticity of demand for the polluting good in country $i, i=A, B$, by $\varepsilon_{i} \equiv-x^{\prime}\left(p_{i}\right) p_{i} / x\left(p_{i}\right) .{ }^{9}$ The symmetric Nash equilibrium in an open economy is characterized (for $i=A, B$ ) by equations (2), (7), (8), (14), (18), and

$$
\begin{aligned}
\frac{\tau_{i}}{p_{i}} & =-\frac{e_{i} \varphi^{\prime}(E)}{p_{i}+\delta \varepsilon_{i}}, \\
t_{i} & =-C^{\prime}\left(e_{i}\right)=\varphi^{\prime}(E) .
\end{aligned}
$$

Comparing these expression with their closed economy counterparts, (19) and (20), shows the impact of tax competition. While $x_{i}$ goes untaxed in a closed economy, this is no longer the case when the economy opens up. Commodity tax competition pushes the equilibrium value of $\tau_{i}$ down to a negative value. It is important to note that the feasibility of this solution is due to the existence of positive emission taxes. No country would want to push its consumer price of $x_{i}$ below its marginal cost. A positive $t_{i}=-C^{\prime}\left(e_{i}\right)$ allows $\tau_{i}$ to be negative as long as $\tau_{i}-C^{\prime}\left(e_{i}\right) e_{i}=p_{i}-C\left(e_{i}\right)>0 .{ }^{10}$ Also observe that equation (21) reflects the well-known "inverse elasticity rule" of optimal commodity taxes: The higher is $\varepsilon$, the smaller will be the required tax.

\footnotetext{
${ }^{9}$ To be precise, this is the elasticity of demand at a symmetric equilibrium.

${ }^{10}$ In the traditional tax competition literature (without emissions), the fact that $p_{i}-C\left(e_{i}\right)$ cannot be negative implies that the Nash equilibrium value of $\tau_{i}$ is zero when lump-sum taxes can be used to finance the provision of public goods. This is why the literature rules lump-sum taxes out.
} 
Turning to optimal emission rule, it remains the same as under the closed-economy solution. This is because the marginal social damage of emissions to a citizen of $i$ is evaluated the same way by its government whether the economy is closed or open. However, this result in itself is not sufficient to compare the equilibrium levels of emissions $\left(e_{i}\right.$ and $E$ ) with their values in the absence of trade. This is an even more interesting question to which we now turn.

\subsection{Pollution technologies, emissions, and welfare}

To address this question, we shall use the property that the closed border solution is effectively a special case (or more precisely the limit) of the open border equilibrium as $\delta$ goes to infinity. Intuitively, this property is not surprising: as the dislike for the foreign good intensifies, it effectively ceases to be a viable alternative to the home-produced good. Consequently, all individuals buy from their country of residence and one is back in an autarchic world. Formally, this convergence property follows directly from the expressions that characterize the closed- and open-economy equilibria. To see this, first note that except for $\tau_{i}$, the two sets of equilibria are defined by identical equations, namely, (14), (15) and (22). The $\tau_{i}$ itself is equal to zero in a closed economy and given by (21) in an open economy. The convergence then follows directly from the property that the right-hand side of equation (21) tends to zero as $\delta$ tends to infinity.

This property enables us to compare the values of the relevant variables under the two equilibria. We do this by studying their comparative statics properties with respect to $\delta$. Specifically, assuming a constant elasticity of demand for $x$, we show in the Appendix, that as $\delta$ increases, the open-economy equilibrium values of $t$ and $E$ decrease while those of $e$ and $p$ increase. This tells us that the open economy values of $t$ and $E$ exceed, and those of $e$ and $p$ fall short of, their closed-equilibrium values. The interesting aspect of this is that it suggests that international trade makes the countries to switch to less polluting technologies (less e) but causes total levels of emissions to increase. In 
the special case of a constant marginal social damage of emissions, $e$ remains unchanged but $p$ continues to decrease resulting in an increase in consumption of polluting goods and consequently in aggregate emissions; see the appendix. The appendix also shows that a country's level of welfare will unambiguously decline as the economy opens up.

We summarize the results of this subsection as

Proposition 4 Economic integration (i) causes the firms to adopt the same or less polluting technologies; (ii) results in price subsidies to polluting goods, (iii) lowers the price of polluting goods; (iv) increases aggregate emissions and (v) lowers welfare.

\section{$5 \quad$ Harmonization of output taxes}

We have seen in the previous sections that the closed and open border solutions are both inefficient and that this is due to a failure of coordination between the countries. It is plain that in the context of our model, the first-best can be restored if the countries set both instruments, output and emission taxes, in a coordinated way. Given symmetry, this can be achieved through a "harmonization" of both tax instruments, i.e., by setting their respective values at a common specified level. In practice, however, such a full coordination may be difficult to achieve. Instead, countries may have to resort to "partial" harmonization of policies i.e., a harmonization which pertains only to a subset of the policy instruments. In our setting this may occur in two ways. On the one hand, one can harmonize output taxes while emission taxes continue to be set independently. On the other hand, it is possible to think of a harmonization of emissions taxes only. In either case, one may wonder whether such partial harmonization is (necessarily) desirable. In particular, one would like to know if it would have the intended impact on the environment and on welfare. Intuitively, the possible concern is that the neutralization of one variable of fiscal competition, may make competition in the other variable even fiercer and that this may give rise to perverse results. For instance, a harmonization of output taxes could result in a lowering of emission taxes and thus in a switch to more 
polluting technologies. This section discusses the harmonization of output taxes; the harmonization of emission taxes is considered in the next section.

Assume that output taxes are set at $\tau=\hat{\tau}$ while emission taxes continue to be set non-cooperatively, exactly as in Section 4 . The Nash equilibrium is then contingent on $\hat{\tau}$ and we write the solutions as $t^{N}(\hat{\tau}), e^{N}(\hat{\tau}), E^{N}(\hat{\tau}), p^{N}(\hat{\tau})$ and $T^{N}(\hat{\tau})$. Further, denote all unrestricted Nash equilibrium values by the superscript $N\left(\tau^{N}, t^{N}, e^{N}, E^{N}, p^{N}\right.$ and $\left.T^{N}\right)$. It is clear that if one were to harmonize $\tau$ at its unrestricted Nash equilibrium value, $\tau^{N}, t$ and all the other variables will also take their (unrestricted) Nash equilibrium values.

It is easy to show that the Nash equilibrium value of $t_{i}$, conditional on $\tau=\hat{\tau}$, is the solution to ${ }^{11}$

$$
-\left[\frac{p_{i}-C\left(e_{i}\right)}{\delta \varepsilon_{i}}+\frac{\tau_{i}}{p_{i}}\right]+\left[\frac{e_{i}}{p_{i}}+\frac{1}{C^{\prime \prime}\left(e_{i}\right) e_{i} \varepsilon_{i}}\right]\left[C^{\prime}\left(e_{i}\right)+\varphi^{\prime}(E)\right]=0 .
$$

Observe that when $\hat{\tau}=\tau^{N}$, the first bracketed expression in the right-hand side of (23) will be zero so that $e^{N}(\hat{\tau})=e^{N}$.

\subsection{Harmonization and the environment}

To study the effects of harmonization on the environment, we have to first determine how harmonization impacts $t^{N}(\hat{\tau})$. To this end, differentiate (23) with respect to $\hat{\tau}$ and evaluate the resulting expression at $\left(t^{N}, \tau^{N}\right)$. To simplify the derivations, we will assume that the marginal social damage of emissions is constant. We have (see the Appendix)

$$
\frac{d t^{N}(\hat{\tau})}{d \hat{\tau}}=\frac{-1}{e+\frac{C^{\prime}(e) e+\delta}{C^{\prime \prime}(e) e[1+(1-\tau / p) \delta \varepsilon / p]}} .
$$

It is clear from $(24)$ that $d t^{N}(\hat{\tau}) / d \hat{\tau}$ can take both positive as well as negative values. The numerical example at the end of this section further demonstrates this point. Now with

\footnotetext{
${ }^{11}$ The best-reply function for $i$ is given by equation (A45) in the Appendix when $\tau_{i}$ is set at $\hat{\tau}$. Of course, one must solve (23) in conjunction with equations (2), (7), (8), (14), and (18).
} 
$e^{N}(\hat{\tau})$ moving in opposite direction to $t^{N}(\hat{\tau})$, equation (24) indicates that harmonizing $\tau$ at "just above" its Nash equilibrium value may have a beneficial as well as a detrimental effect on the choice of a polluting technology.

Next, to determine what happens to aggregate emissions, differentiate $E=2 e x(p)$ with respect to $\hat{\tau}$. After a bit of algebraic manipulation, we get

$$
\frac{d E^{N}(\hat{\tau})}{d \hat{\tau}}=2 x(p)\left[\frac{\frac{1}{\delta \varepsilon}-\frac{C^{\prime}(e) e}{\delta p}-\frac{\tau}{p^{2}}}{\frac{1}{\delta \varepsilon}+\frac{1}{p}-\frac{\tau}{p^{2}}}\right] \frac{d e^{N}(\hat{\tau})}{d \hat{\tau}} .
$$

The bracketed expression in the right-hand side of $(25)$ is positive due to the negative signs of $\tau$ and $C^{\prime}(e)$. Consequently, with the effect of harmonization on $e^{N}(\hat{\tau})$ being ambiguous, equation (25) indicates that the effect of harmonization on $E$ is also ambiguous. Nevertheless we have that $e$ and $E$ always move positively together.

\subsection{Harmonization and welfare}

So far, we have shown that harmonizing $\tau_{i}$ at a level which is above the unrestricted Nash equilibrium does not necessarily improve the environment. Let us now study the impact of such a policy on overall welfare. This is of course affected by what happens to the environment; but it also depends on other factors, particularly tax distortions. From (13), a country's welfare at a (restricted) symmetric Nash equilibrium with $\tau=\hat{\tau}$ is given by

$$
W^{S}\left(t^{N}(\hat{\tau}), \hat{\tau}\right)=m-p^{N}(\hat{\tau}) x\left(p^{N}(\hat{\tau})\right)+h\left(x\left(p^{N}(\hat{\tau})\right)\right)+T^{N}(\hat{\tau})-\varphi\left(E^{N}(\hat{\tau})\right),
$$

where we have dropped the $i$ subscript for simplicity. Differentiating this expression totally with respect to $\hat{\tau}$ yields:

$$
\frac{d W^{S}\left(t^{N}(\hat{\tau}), \hat{\tau}\right)}{d \hat{\tau}}=\frac{\partial W^{S}\left(t^{N}(\hat{\tau}), \hat{\tau}\right)}{\partial \hat{\tau}}+\frac{\partial W^{S}\left(t^{N}(\hat{\tau}), \hat{\tau}\right)}{\partial t^{N}(\hat{\tau})} \frac{d t^{N}(\hat{\tau})}{d \hat{\tau}} .
$$


In the Appendix, we derive the expressions for $\partial W^{S} / \partial \hat{\tau}$ and $\partial W^{S} / \partial t^{N}(\hat{\tau})$. It follows from these expressions and (24) that at $\hat{\tau}=\tau^{N}$,

$$
\frac{d W^{S}\left(t^{N}(\hat{\tau}), \hat{\tau}\right)}{d \hat{\tau}}=-x(p)\left\{\frac{\varphi^{\prime}(E)\left[\frac{p-C(e)}{\delta^{2} \varepsilon}+\frac{\varphi^{\prime}(E) e}{\delta p}-\frac{\hat{\tau}}{p^{2}}\right]-\frac{\hat{\tau}}{\delta \varepsilon e}}{\frac{1}{\delta \varepsilon}+\frac{1}{p}-\frac{\hat{\tau}}{p^{2}}}\right\} \frac{d e^{N}(\hat{\tau})}{d \hat{\tau}} .
$$

Note that the bracketed expression in the right-hand side of (28) is always positive. Equation (28) thus tells us that welfare always moves negatively with $e$ (and $E$ since $e$ and $E$ move together).

\subsection{Numerical illustration}

Consider a specification of our model with quadratic per unit costs, constant marginal social damage (of total emission) and constant elasticity demand. We thus assume the following functional forms:

$$
\begin{aligned}
C(e) & =\frac{b(1-e)^{2}}{2}, \\
\varphi(E) & =\varphi E, \\
h(x) & =\frac{x^{1-1 / \varepsilon}}{1-1 / \varepsilon} .
\end{aligned}
$$

Observe that demand for $x$ is given by

$$
x=p^{-\varepsilon},
$$

where $\varepsilon$ is the constant elasticity of demand equal (in absolute value).

Given these specifications, we derive the Nash equilibrium allocations under open international borders (from equations (2), (7), (8), (14), (18), (21), and (22)). Then, we solve the problem again at a value exceeding its unrestricted Nash equilibrium value (by dropping equations (21)-(22) and replacing them with the set value of $\tau$ and (23)). Table 1 reports the equilibrium with and without harmonization for two different values of $\delta: 0.1$ and 0.01 . All other parameters take the same values of $b=0.40, \varphi=0.25$ and $\varepsilon=0.20$. In the first example, $t^{N}(\hat{\tau})$ decreases. The result is a higher value for $e$ and 
Table 1. Commodity tax harmonization

\begin{tabular}{|c|c||c|ccc|cc|}
\hline & \multicolumn{7}{|c|}{$(\delta=0.1)$} \\
\hline & $\tau$ & $t$ & $e$ & $E$ & $W^{S}$ & $p$ & $x(p)$ \\
\hline Absent harmonization & -0.07737 & 0.25000 & 0.37500 & 1.20219 & 3.53635 & 0.09450 & 1.60292 \\
With harmonization & -0.07700 & 0.24907 & 0.37732 & 1.20955 & 3.53544 & 0.09453 & 1.60284 \\
\hline \hline & \multicolumn{7}{|c|}{$(\delta=0.01)$} \\
\hline & $\tau$ & $t$ & $e$ & $E$ & $W^{S}$ & $p$ & $x(p)$ \\
\hline Absent harmonization & -0.09147 & 0.25000 & 0.37500 & 1.24168 & 3.52696 & 0.08040 & 1.65557 \\
With harmonization & -0.09130 & 0.25111 & 0.37223 & 1.23072 & 3.52855 & 0.08099 & 1.65316 \\
\hline
\end{tabular}

$E$, and a lower value for welfare. In the second example, $t^{N}(\hat{\tau})$ increases. The result is a lower value for $e$ and $E$, and a higher value for welfare.

The results of this section are summarized as

Proposition 5 Assume countries $A$ and $B$ harmonize their commodity tax rates, at $\tau=\hat{\tau}$ which is "just above" its unrestricted Nash equilibrium value, $\tau^{N}$; they continue to compete in emission taxes. We have, assuming a constant marginal social damage of emissions,

(i) Harmonizing $\tau_{i}$ at $\hat{\tau}>\tau^{N}$ may increase $t_{i}$. Under this circumstance, firms opt for less polluting technologies. Then, aggregate emissions also decrease and welfare improves.

(ii) Harmonizing $\tau_{i}$ at $\hat{\tau}>\tau^{N}$ may lower $t_{i}$. Under this circumstance, firms opt for more polluting technologies. Then, aggregate emissions also increase and welfare deteriorates.

\section{Emission tax harmonization}

We now turn to the harmonization of taxes at $t=\hat{t}$. Output taxes continue to be set non-cooperatively with each country maximizing its own residents' welfare. We study the restricted Nash equilibrium conditional on $t=\hat{t}$. The equilibrium value of $\tau_{i}$, 
denoted $\tau^{N}(\hat{t})$, is the solution to ${ }^{12}$

$$
-\left[\frac{p_{i}-C\left(e_{i}\right)}{\delta \varepsilon_{i}}+\frac{\tau_{i}}{p_{i}}\right]+\frac{e_{i}}{p_{i}}\left[C^{\prime}\left(e_{i}\right)+\varphi^{\prime}(E)\right]=0 .
$$

We also introduce the obvious notations $e^{N}(\hat{t}), E^{N}(\hat{t})$ and $p^{N}(\hat{t})$. Observe that when $t$ is unrestricted, the bracketed expression in the left-hand side of (33) will be zero so that $\tau$ will also take its unrestricted Nash equilibrium value, $\tau^{N}$.

\subsection{Harmonization and the environment}

With $t_{i}$ fixed, per unit emission, $e_{i}$, is determined. Consequently, when the emission tax rate is set above its unrestricted Nash equilibrium value, it follows immediately that less polluting technologies will be used. However, the impact of this on $E$, and thus on the overall environmental quality, is not as obvious. There is another factor here; namely what happens to the aggregate production of the polluting good. This in turn depends on $p$ and thus on the Nash equilibrium level of $\tau, \tau^{N}(\hat{t})$. To study these additional effects, we differentiate (33) with respect to $\hat{t}$ and evaluate the resulting expression at $\left(t^{N}, \tau^{N}\right)$. To simplify the derivations, we continue to assume that the marginal social damage of emissions is constant. We have (see the Appendix)

$$
\frac{d \tau^{N}(\hat{t})}{d \hat{t}}=-e-\frac{C^{\prime}(e)}{C^{\prime \prime}(e)[1+(1-\tau / p) \delta \varepsilon / p]} .
$$

It is clear that the sign of the above expression is ambiguous. Nevertheless the value of $d \tau^{N}(\hat{t}) / d \hat{t}$ implies that $p^{N}(\hat{t})$ is increasing in $\hat{t}$ at $\hat{t}=t^{N}$. To see this, differentiate $p=C(e)-C^{\prime}(e) e+\tau$ with respect to $\hat{t}$ :

$$
\frac{d p}{d \hat{t}}=e+\frac{d \tau}{d \hat{t}}
$$

Substituting from (34) in above yields

$$
\frac{d p^{N}(\hat{t})}{d \hat{t}}=-\frac{C^{\prime}(e)}{C^{\prime \prime}(e)[1+(1-\tau / p) \delta \varepsilon / p]},
$$

\footnotetext{
${ }^{12}$ The best-reply function for $i$ is given by equation (A46) in the Appendix when $t_{i}$ is set at $\hat{t}$. Of course, one must solve (33) in conjunction with equations (2), (7), (8), (14), and (18).
} 
which is positive when evaluated at $\hat{t}=t^{N}$. This follows from the convexity of $C($.$) and$ the fact that $\tau^{N}<0$.

Armed with this result, one can easily determine the effect of harmonization on aggregate emissions. Differentiate $E=2 e x(p)$ with respect to $\hat{t}$. After a bit of algebraic manipulation, we get

$$
\frac{d E^{N}(\hat{t})}{d \hat{t}}=-2 x(p)\left[\frac{1}{C^{\prime \prime}(e)}+\frac{e \varepsilon}{p} \frac{d p^{N}(\hat{t})}{d \hat{t}}\right] .
$$

With $d p^{N}(\hat{t}) / d \hat{t}>0$, the bracketed expression in the right-hand side of (36) will also be positive. Consequently, equation (36) indicates that harmonizing $t$ at just above its unrestricted Nash equilibrium value, reduces aggregate emissions.

\subsection{Harmonization and welfare}

We have shown that harmonizing the emission tax rate reduces per unit as well as aggregate emissions. Consequently, one would expect that this form of partial harmonization does have a positive impact on overall welfare. We now show that this conjecture is indeed correct.

Use (13) to write a country's welfare, at a symmetric Nash equilibrium with $t=\hat{t}$, $\operatorname{as}^{13}$

$$
W^{S}\left(\tau^{N}(\hat{t}), \hat{t}\right)=m-p^{N}(\hat{t}) x\left(p^{N}(\hat{t})\right)+h\left(x\left(p^{N}(\hat{t})\right)\right)+T^{N}(\hat{t})-\varphi\left(E^{N}(\hat{t})\right) .
$$

Differentiate $W^{S}\left(\tau^{N}(\hat{t}), \hat{t}\right)$ totally with respect to $\hat{t}$ to get

$$
\frac{d W^{S}\left(\tau^{N}(\hat{t}), \hat{t}\right)}{d \hat{t}}=\frac{\partial W^{S}\left(\tau^{N}(\hat{t}), \hat{t}\right)}{\partial \hat{t}}+\frac{\partial W^{S}\left(\tau^{N}(\hat{t}), \hat{t}\right)}{\partial \tau^{N}(\hat{t})} \frac{d \tau^{N}(\hat{t})}{d \hat{t}} .
$$

Next, substitute the expressions for $\partial W^{S} / \partial \hat{\tau}$ and $\partial W^{S} / \partial t^{N}(\hat{\tau})$ (derived in the Appendix), and $d \tau^{N}(\hat{t}) / d \hat{t}$ from (34), in (38) and simplify. We have at $\hat{t}=t^{N}$,

$$
\frac{d W^{S}\left(\tau^{N}(\hat{t}), \hat{t}\right)}{d \hat{t}}=x(p) \varepsilon\left[\frac{p-C(e)}{\delta \varepsilon}+\frac{\varphi^{\prime}(E) e}{p}\right] \frac{d p^{N}(\hat{t})}{d \hat{t}}+\frac{x(p) \varphi^{\prime}(E)}{C^{\prime \prime}(e)}>0 .
$$

\footnotetext{
${ }^{13}$ We have again dropped the $i$ subscript for ease in notation.
} 
The sign of (39) follows from the fact that $d p^{N}(\hat{t}) / d \hat{t}>0$ and the convexity of $C($.$) .$

The results of this section are summarized as

Proposition 6 Assume countries $A$ and $B$ harmonize their emission tax rates, at $t=$

$\hat{t}$ which is "just above" its unrestricted Nash equilibrium value, $t^{N}$; they continue to compete in commodity taxes. We have, assuming a constant marginal social damage of emissions, (i) firms opt for a less polluting technology, (ii) aggregate emissions decline and (iii) overall welfare increases.

\section{Conclusion}

This paper has studied competition in environmental taxes in the presence of a global negative externality. The distinctive feature of the study has been in its differentiation between the choice of polluting technologies and aggregate emissions. The two need not move positively together. Indeed, one main lesson that has emerged is that the possiblity of trade causes the firms to adopt the same or less polluting technologies, but it nevertheless increases aggregate emissions and lowers welfare.

Secondly, we studied the ramifications of partial harmonization policies. With commodity tax harmonization, we found that if one were to harmonize the tax on the polluting good at its unrestricted Nash equilibrium value, it will lead the equilibrium emission tax to either increase or decrease. If the emission tax increases, firms will adopt less polluting technologies. In turn, this will lead to a lowering of aggregate emissions and improvement in overall welfare. On the other hand, if emission tax goes down, firms will choose more polluting technologies. Under this circumstance, aggregate emissions will increase and welfare deteriorates.

Turning to harmonization of emission taxes, it is plain that harmonizing emission taxes at a value above their unrestricted Nash equilibrium, would lead the firms to adopt a less polluting technology. Interestingly, we showed that this policy also causes aggregate emissions to decline and overall welfare to increase. 


\section{Appendix}

Derivation of $(4),(5),(6)$ : We have

$$
\begin{gathered}
T_{A}= \begin{cases}\int_{\tilde{\theta}}^{1}\left[p_{A}-C\left(e_{A}\right)\right] x_{A}^{A} d \theta & \text { if } p_{A} \geq p_{B}, \\
\int_{\tilde{\theta}}^{0}\left[p_{A}-C\left(e_{A}\right)\right] x_{A}^{B} d \theta+\int_{0}^{1}\left[p_{A}-C\left(e_{A}\right)\right] x_{A}^{A} d \theta & \text { if } p_{A}<p_{B},\end{cases} \\
T_{B}= \begin{cases}\int_{-\tilde{\theta}}^{0}\left[p_{B}-C\left(e_{B}\right)\right] x_{B}^{B} d \theta+\int_{0}^{\tilde{\theta}}\left[p_{B}-C\left(e_{B}\right)\right] x_{B}^{A} d \theta & \text { if } p_{A} \geq p_{B}, \\
\int_{-1}^{\tilde{\theta}}\left[p_{B}-C\left(e_{B}\right)\right] x_{B}^{B} d \theta & \text { if } p_{A}<p_{B} .\end{cases}
\end{gathered}
$$

And

$$
E= \begin{cases}\int_{-\bar{\theta}}^{0} e_{B} x_{B}^{B} d \theta+\int_{0}^{\tilde{\theta}} e_{B} x_{B}^{A} d \theta+\int_{\tilde{\theta}}^{1} e_{A} x_{A}^{A} d \theta & \text { if } p_{A} \geq p_{B} \\ \int_{-1}^{\tilde{\theta}} e_{B} x_{B}^{B} d \theta+\int_{\tilde{\theta}}^{0} e_{A} x_{A}^{B} d \theta+\int_{0}^{1} e_{A} x_{A}^{A} d \theta & \text { if } p_{A}<p_{B}\end{cases}
$$

Simplifying yields equations (4)-(5) and (6) in the text.

Differentiability of $T_{A}\left(p_{A}, e_{A} ; p_{B}\right), T_{B}\left(p_{B}, e_{B} ; p_{A}\right)$ and $E\left(p_{A}, p_{B}, e_{A}, e_{B}\right)$ : Partially differentiate equations (4) and (6) with respect to $p_{A}$ and $e_{A}$, and equations (5) and (6) with respect to $p_{B}$ and $e_{B}$. We have

$$
\frac{\partial T_{A}}{\partial p_{A}}= \begin{cases}(1-\tilde{\theta}) x\left(p_{A}\right)-\frac{1}{\delta}\left[p_{A}-C\left(e_{A}\right)\right] x\left(p_{A}\right)+\left[p_{A}-C\left(e_{A}\right)\right](1-\tilde{\theta}) x^{\prime}\left(p_{A}\right) & \text { if } p_{A} \geq p_{B} \\ x\left(p_{A}\right)+\int_{\tilde{\theta}}^{0} x\left(p_{A}-\delta \theta\right) d \theta+\left[p_{A}-C\left(e_{A}\right)\right]\left[x^{\prime}\left(p_{A}\right)-\frac{1}{\delta} x\left(p_{A}\right)\right] & \text { if } p_{A}<p_{B} .\end{cases}
$$

$$
\begin{gathered}
\frac{\partial T_{B}}{\partial p_{B}}= \begin{cases}x & \left(p_{B}\right)+\int_{0}^{\tilde{\theta}} x\left(p_{B}+\delta \theta\right) d \theta+\left[p_{B}-C\left(e_{B}\right)\right]\left[x^{\prime}\left(p_{B}\right)-\frac{1}{\delta} x\left(p_{B}\right)\right] \\
(1+\tilde{\theta}) x\left(p_{B}\right)-\frac{1}{\delta}\left[p_{B}-C\left(e_{B}\right)\right] x\left(p_{B}\right)+\left[p_{B}-C\left(e_{B}\right)\right](1+\tilde{\theta}) x^{\prime}\left(p_{B}\right)\end{cases} \\
\frac{\partial E}{\partial p_{A}}= \begin{cases}\frac{1}{\delta} e_{B} x\left(p_{B}+\delta \tilde{\theta}\right)-\frac{1}{\delta} e_{A} x\left(p_{A}\right)+(1-\tilde{\theta}) e_{A} x^{\prime}\left(p_{A}\right) & \text { if } p_{A} \geq p_{B}, \\
\frac{1}{\delta} e_{B} x\left(p_{B}\right)+e_{A}\left[x^{\prime}\left(p_{A}\right)-\frac{1}{\delta} x\left(p_{A}\right)\right] & \text { if } p_{A}<p_{B} .\end{cases} \\
\frac{\partial E}{\partial p_{B}}= \begin{cases}e_{B}\left[x^{\prime}\left(p_{B}\right)-\frac{1}{\delta} x\left(p_{B}\right)\right]+\frac{1}{\delta} e_{A} x\left(p_{A}\right) & \text { if } p_{A} \geq p_{B} \\
-\frac{1}{\delta} e_{B} x\left(p_{B}\right)+(1+\tilde{\theta}) e_{B} x^{\prime}\left(p_{B}\right)+\frac{1}{\delta} e_{A} x\left(p_{A}-\delta \tilde{\theta}\right) & \text { if } p_{A}<p_{B}\end{cases} \\
\frac{\partial T_{A}}{\partial e_{A}}= \begin{cases}-C^{\prime}\left(e_{A}\right)(1-\tilde{\theta}) x\left(p_{A}\right) & \text { if } p_{A} \geq p_{B} \\
-C^{\prime}\left(e_{A}\right)\left[x\left(p_{A}\right)+\int_{\tilde{\theta}}^{0} x\left(p_{A}-\delta \theta\right) d \theta\right] & \text { if } p_{A}<p_{B} .\end{cases} \\
\frac{\partial T_{B}}{\partial e_{B}}= \begin{cases}-C^{\prime}\left(e_{B}\right)\left[x\left(p_{B}\right)+\int_{0}^{\tilde{\theta}} x\left(p_{B}+\delta \theta\right) d \theta\right] & \text { if } p_{A} \geq p_{B} \\
-C^{\prime}\left(e_{B}\right)(1+\tilde{\theta}) x\left(p_{B}\right) & \text { if } p_{A}<p_{B} .\end{cases}
\end{gathered}
$$




$$
\begin{aligned}
& \frac{\partial E}{\partial e_{A}}= \begin{cases}(1-\tilde{\theta}) x\left(p_{A}\right) & \text { if } p_{A} \geq p_{B} \\
\int_{\tilde{\theta}}^{0} x\left(p_{A}-\delta \theta\right) d \theta+x\left(p_{A}\right) & \text { if } p_{A}<p_{B}\end{cases} \\
& \frac{\partial E}{\partial e_{B}}= \begin{cases}\int_{0}^{\tilde{\theta}} x\left(p_{B}+\delta \theta\right) d \theta+x\left(p_{B}\right) & \text { if } p_{A} \geq p_{B} \\
(1+\tilde{\theta}) x\left(p_{B}\right) & \text { if } p_{A}<p_{B}\end{cases}
\end{aligned}
$$

where, in the derivations of (A4)-(A7), we have utilized the following expressions:

$$
\begin{aligned}
\frac{\partial}{\partial p_{A}} \int_{\tilde{\theta}}^{0} x\left(p_{A}-\delta \theta\right) d \theta & =\int_{\tilde{\theta}}^{0} x^{\prime}\left(p_{A}-\delta \theta\right) d \theta-x\left(p_{A}-\delta \tilde{\theta}\right) \frac{\partial \tilde{\theta}}{\partial p_{A}} \\
& =-\frac{1}{\delta}\left[x\left(p_{A}-\delta \theta\right)\right]_{\theta=\tilde{\theta}}^{\theta=0}-\frac{1}{\delta} x\left(p_{A}-\delta \tilde{\theta}\right)=-\frac{1}{\delta} x\left(p_{A}\right), \\
\frac{\partial}{\partial p_{B}} \int_{0}^{\tilde{\theta}} x\left(p_{B}+\delta \theta\right) d \theta & =\int_{0}^{\tilde{\theta}} x^{\prime}\left(p_{B}+\delta \theta\right) d \theta-x\left(p_{B}+\delta \tilde{\theta}\right) \frac{\partial \tilde{\theta}}{\partial p_{B}} \\
& =\frac{1}{\delta}\left[x\left(p_{B}+\delta \theta\right)\right]_{\theta=0}^{\theta=\tilde{\theta}}-\frac{1}{\delta} x\left(p_{B}+\delta \tilde{\theta}\right)=-\frac{1}{\delta} x\left(p_{B}\right) .
\end{aligned}
$$

Evaluating expressions (A4)-(A11) at $p_{A}=p_{B}$ and simplifying, we get an identical expression for the left- and the right-hand derivatives of each of the functions $T_{A}(),. T_{B}($. and $E($.$) . They are all continuous and given by, for i=A, B,{ }^{14}$

$$
\begin{aligned}
\frac{\partial T_{i}}{\partial p_{i}} & =x\left(p_{i}\right)-\left[p_{i}-C\left(e_{i}\right)\right]\left[\frac{x\left(p_{i}\right)}{\delta}-x^{\prime}\left(p_{i}\right)\right], \\
\frac{\partial E}{\partial p_{i}} & =e_{i} x^{\prime}\left(p_{i}\right), \\
\frac{\partial T_{i}}{\partial e_{i}} & =-C^{\prime}\left(e_{i}\right) x\left(p_{i}\right), \\
\frac{\partial E}{\partial e_{i}} & =x\left(p_{i}\right) .
\end{aligned}
$$

Characterizations and differentiability of $W_{A}\left(p_{A}, T_{A}, E ; p_{B}\right), W_{B}\left(p_{B}, T_{B}, E ; p_{A}\right)$ : To simplify the exposition of the proof, first calculate the following expressions based on the definition of $F(p)$ in (10).

$$
\int_{0}^{\tilde{\theta}}\left[h\left(x\left(p_{B}+\delta \theta\right)\right)-\left(p_{B}+\delta \theta\right) x\left(p_{B}+\delta \theta\right)\right] d \theta=\frac{1}{\delta}\left[F\left(p_{A}\right)-F\left(p_{B}\right)\right],
$$

\footnotetext{
${ }^{14}$ One can easily show that the same properties hold for all other partial derivatives of $T_{A}(),. T_{B}($. and $E($.$) .$
} 


$$
\begin{aligned}
\int_{\tilde{\theta}}^{0}\left[h\left(x\left(p_{A}-\delta \theta\right)\right)-\left(p_{A}-\delta \theta\right) x\left(p_{A}-\delta \theta\right)\right] d \theta & =-\frac{1}{\delta}\left[F\left(p_{A}\right)-F\left(p_{B}\right)\right] \\
F^{\prime}\left(p_{i}\right)= & h\left(x\left(p_{i}\right)\right)-p_{i} x\left(p_{i}\right), \quad i=A, B \\
\frac{\partial}{\partial p_{A}} \tilde{\theta}\left[h\left(x\left(p_{A}\right)\right)-p_{A} x\left(p_{A}\right)\right] & =\frac{1}{\delta}\left[h\left(x\left(p_{A}\right)\right)-p_{A} x\left(p_{A}\right)\right]+\tilde{\theta}\left[h^{\prime}\left(x\left(p_{A}\right)\right) x^{\prime}\left(p_{A}\right)\right. \\
& \left.-x\left(p_{A}\right)-p_{A} x^{\prime}\left(p_{A}\right)\right]=\frac{1}{\delta} F^{\prime}\left(p_{A}\right)-\tilde{\theta} x\left(p_{A}\right), \\
\frac{\partial}{\partial p_{B}} \tilde{\theta}\left[h\left(x\left(p_{B}\right)\right)-p_{B} x\left(p_{B}\right)\right] & =-\frac{1}{\delta}\left[h\left(x\left(p_{B}\right)\right)-p_{B} x\left(p_{B}\right)\right]+\tilde{\theta}\left[h^{\prime}\left(x\left(p_{B}\right)\right) x^{\prime}\left(p_{B}\right)\right. \\
& \left.-x\left(p_{B}\right)-p_{B} x^{\prime}\left(p_{B}\right)\right]=-\frac{1}{\delta} F^{\prime}\left(p_{B}\right)-\tilde{\theta} x\left(p_{B}\right)
\end{aligned}
$$

Characterizations of $W_{A}\left(p_{A}, T_{A}, E ; p_{B}\right), W_{B}\left(p_{B}, T_{B}, E ; p_{A}\right)$ : Consider the case where $p_{A} \geq p_{B}$. We have $\tilde{\theta} \geq 0$ and

$$
\begin{aligned}
W_{A}= & \int_{0}^{\tilde{\theta}}\left[m+h\left(x\left(p_{B}+\delta \theta\right)\right)-\left(p_{B}+\delta \theta\right) x\left(p_{B}+\delta \theta\right)+T_{A}-\varphi(E)\right] d \theta+ \\
& \int_{\tilde{\theta}}^{1}\left[m+h\left(x\left(p_{A}\right)\right)-p_{A} x\left(p_{A}\right)+T_{A}-\varphi(E)\right] d \theta, \\
= & U_{A}-\int_{0}^{\tilde{\theta}}\left[h\left(x\left(p_{A}\right)\right)-p_{A} x\left(p_{A}\right)\right] d \theta+\int_{0}^{\tilde{\theta}}\left[h\left(x\left(p_{B}+\delta \theta\right)\right)-\left(p_{B}+\delta \theta\right) x\left(p_{B}+\delta \theta\right)\right] d \theta, \\
= & U_{A}-\tilde{\theta}\left[h\left(x\left(p_{A}\right)\right)-p_{A} x\left(p_{A}\right)\right]+\frac{1}{\delta}\left[F\left(p_{A}\right)-F\left(p_{B}\right)\right] . \\
W_{B}= & \int_{-1}^{0}\left[m+h\left(x\left(p_{B}\right)\right)-p_{B} x\left(p_{B}\right)+T_{B}-\varphi(E)\right] d \theta, \\
= & U_{B} .
\end{aligned}
$$

where we have made use of equations (A18)-(A19) and the definition of $U_{i}(i=A, B)$ in (9).

Similarly, using (A18)-(A19) and the definition of $U_{i}(i=A, B)$ for the case $p_{A}<p_{B}$, we have

$$
\begin{aligned}
W_{A} & =\int_{0}^{1}\left[m+h\left(x\left(p_{A}\right)\right)-p_{A} x\left(p_{A}\right)+T_{A}-\varphi(E)\right] d \theta, \\
& =U_{A} .
\end{aligned}
$$




$$
\begin{aligned}
W_{B}= & \int_{-1}^{\tilde{\theta}}\left[m+h\left(x\left(p_{B}\right)\right)-p_{B} x\left(p_{B}\right)+T_{B}-\varphi(E)\right] d \theta+ \\
& \int_{\tilde{\theta}}^{0}\left[m+h\left(x\left(p_{A}-\delta \theta\right)\right)-\left(p_{A}-\delta \theta\right) x\left(p_{A}-\delta \theta\right)+T_{B}-\varphi(E)\right] d \theta, \\
= & U_{B}-\int_{\tilde{\theta}}^{0}\left[h\left(x\left(p_{B}\right)\right)-p_{B} x\left(p_{B}\right)\right] d \theta+\int_{\tilde{\theta}}^{0}\left[h\left(x\left(p_{A}-\delta \theta\right)\right)-\left(p_{A}-\delta \theta\right) x\left(p_{A}-\delta \theta\right)\right] d \theta, \\
= & U_{B}+\tilde{\theta}\left[h\left(x\left(p_{B}\right)\right)-p_{B} x\left(p_{B}\right)\right]-\frac{1}{\delta}\left[F\left(p_{A}\right)-F\left(p_{B}\right)\right] .
\end{aligned}
$$

Continuous differentiability: Differentiating equation (11) with respect to $p_{A}$ and equation (12) with respect to $p_{B}$, making use of (A21)-(A22), yields

$$
\begin{aligned}
& \frac{\partial W_{A}}{\partial p_{A}}= \begin{cases}\frac{\partial U_{A}}{\partial p_{A}}+\frac{1}{\delta} F^{\prime}\left(p_{A}\right)-\left[\frac{1}{\delta} F^{\prime}\left(p_{A}\right)-\tilde{\theta} x\left(p_{A}\right)\right] & \text { if } p_{A} \geq p_{B}, \\
\frac{\partial U_{A}}{\partial p_{A}} & \text { if } p_{A}<p_{B} .\end{cases} \\
& \frac{\partial W_{B}}{\partial p_{B}}= \begin{cases}\frac{\partial U_{B}}{\partial p_{B}} & \text { if } p_{A} \geq p_{B} \\
\frac{\partial U_{B}}{\partial p_{B}}+\frac{1}{\delta} F^{\prime}\left(p_{B}\right)-\frac{1}{\delta} F^{\prime}\left(p_{B}\right)-\tilde{\theta} x\left(p_{B}\right) & \text { if } p_{A}<p_{B} .\end{cases}
\end{aligned}
$$

The equality of left- and right-hand derivatives result follows immediately from the fact that at $p_{A}=p_{B}, \tilde{\theta}=0 .{ }^{15}$

Proof of Proposition 1: The first-order conditions are:

$$
\begin{aligned}
& \frac{\partial W_{i}^{S}}{\partial \tau_{i}}=\frac{\partial W_{i}^{S}}{\partial p_{i}}=-x\left(p_{i}\right)+\left.\frac{\partial T_{i}}{\partial p_{i}}\right|_{e_{i}}-\left.\varphi^{\prime}(E) \frac{\partial E}{\partial p_{i}}\right|_{e_{i}}=0 \\
& \frac{\partial W_{i}^{S}}{\partial t_{i}}=\left.\frac{\partial W_{i}^{S}}{\partial p_{i}} \frac{\partial p_{i}}{\partial t_{i}}\right|_{\tau_{i}}+\left.\frac{\partial W_{i}^{S}}{\partial t_{i}}\right|_{p_{i}}=\left.\frac{\partial W_{i}^{S}}{\partial p_{i}} \frac{\partial p_{i}}{\partial t_{i}}\right|_{\tau_{i}}+\left.\frac{\partial T_{i}}{\partial t_{i}}\right|_{p_{i}}-\left.\varphi^{\prime}(E) \frac{\partial E}{\partial t_{i}}\right|_{p_{i}}=0 .
\end{aligned}
$$

Simplifying (A29)-(A30), via differentiation of equations (14)-(15), we have

$$
\begin{aligned}
& \frac{\partial W_{i}^{S}}{\partial \tau_{i}}=-x\left(p_{i}\right)+x\left(p_{i}\right)+\left[p_{i}-C\left(e_{i}\right)\right] x^{\prime}\left(p_{i}\right)-\varphi^{\prime}(E) 2 e_{i} x^{\prime}\left(p_{i}\right)=0, \\
& \frac{\partial W_{i}^{S}}{\partial t_{i}}=\left.\frac{\partial W_{i}^{S}}{\partial p_{i}} \frac{\partial p_{i}}{\partial t_{i}}\right|_{\tau_{i}}-C^{\prime}\left(e_{i}\right) \frac{\partial e_{i}}{\partial t_{i}} x\left(p_{i}\right)-\varphi^{\prime}(E)\left[2 \frac{\partial e_{i}}{\partial t_{i}} x\left(p_{i}\right)\right]=0 .
\end{aligned}
$$

Further algebraic manipulation of (A31)-(A32) simplifies these equations into:

$$
\begin{aligned}
& \frac{\partial W_{i}^{S}}{\partial \tau_{i}}=\left\{\tau_{i}-\left[C^{\prime}\left(e_{i}\right)+2 \varphi^{\prime}(E)\right] e_{i}\right\} x^{\prime}\left(p_{i}\right)=0, \\
& \frac{\partial W_{i}^{S}}{\partial t_{i}}=\frac{\partial W_{i}^{S}}{\partial \tau_{i}} e_{i}+\frac{x\left(p_{i}\right)}{C^{\prime \prime}\left(e_{i}\right)}\left[C^{\prime}\left(e_{i}\right)+2 \varphi^{\prime}(E)\right]=0,
\end{aligned}
$$

\footnotetext{
${ }^{15}$ One can easily show that the same properties hold for all other partial derivatives of $W_{i}(i=A, B)$.
} 
where we have substituted $\tau_{i}-C^{\prime}\left(e_{i}\right) e_{i}$ for $p_{i}-C\left(e_{i}\right)$.

To prove (17), set $\partial W_{i}^{S} / \partial \tau_{i}=0$ in (A34) and simplify. Second, to prove $\tau_{i}=0$, set $-C^{\prime}\left(e_{i}\right)=2 \varphi^{\prime}(E)$ in (A33) and simplify.

Proof of Proposition 2: Part (i). Summarize country $i$ 's problem through the Lagrangian

$$
\Delta_{i}=m+h\left(x\left(p_{i}\right)\right)-p_{i} x\left(p_{i}\right)+T_{i}-\varphi(E)
$$

where $E=e_{i} x\left(p_{i}\right)+e_{j} x\left(p_{j}\right)$. Thus the difference with the optimization problem of Proposition 1 is only in the treatment of $E$. The proof will then be identical to the proof of Proposition 1 except that $\varphi^{\prime}(E)$ replaces $2 \varphi^{\prime}(E)$ everywhere.

To prove parts (ii)-(iii), consider the system of equations

$$
\begin{aligned}
-C^{\prime}(e) & =\alpha \varphi^{\prime}(E), \\
E & =2 e x(p), \\
p & =C(e)-C^{\prime}(e) e,
\end{aligned}
$$

where $\alpha$ is a positive constant. These equations determine $e, E$ and $p$ as a function of $\alpha$. These values correspond to the second-best when $\alpha=2$ and the closed-economy solution when $\alpha=1$. (Recall that in both cases, $\tau=0$ ).

Next, differentiate equations (A36)-(A38) totally with respect to $\alpha$ and simplify. We have

$$
\begin{aligned}
& \frac{d e}{d \alpha}=\frac{-\varphi^{\prime}(E)}{C^{\prime \prime}(e)+2 x(p) \alpha \varphi^{\prime \prime}(E)\left[1+C^{\prime \prime}(e) e^{2} \varepsilon / p\right]}<0, \\
& \frac{d p}{d \alpha}=\frac{C^{\prime \prime}(e) e \varphi^{\prime}(E)}{C^{\prime \prime}(e)+2 x(p) \alpha \varphi^{\prime \prime}(E)\left[1+C^{\prime \prime}(e) e^{2} \varepsilon / p\right]}>0, \\
& \frac{d E}{d \alpha}=\frac{-2 x(p) \varphi^{\prime}(E)\left[1+C^{\prime \prime}(e) e^{2} \varepsilon / p\right]}{C^{\prime \prime}(e)+2 x(p) \alpha \varphi^{\prime \prime}(E)\left[1+C^{\prime \prime}(e) e^{2} \varepsilon / p\right]}<0 .
\end{aligned}
$$

Parts (ii)-(iii) follow immediately from the signs of (A39)-(A41) which hold for all values of $\alpha>0$, given the convexity of $C($.$) and \varphi($.$) .$ 
Proof of Proposition 3: To derive the best-reply functions of each country, differentiate equations (11)-(12) with respect to the instrument employed. Thus, let $I_{i}$ stand for $\tau_{i}, t_{i}$ or $e_{i}$. We have:

$$
\begin{gathered}
\frac{\partial W_{A}}{\partial I_{A}}= \begin{cases}\frac{\partial U_{A}}{\partial I_{A}}+\frac{\partial}{\partial I_{A}}\left[\frac{1}{\delta}\left[F\left(p_{A}\right)-F\left(p_{B}\right)\right]-\tilde{\theta}\left[h\left(x\left(p_{A}\right)\right)-p_{A} x\left(p_{A}\right)\right]\right] & \text { if } p_{A} \geq p_{B} \\
\frac{\partial U_{A}}{\partial I_{A}} & \text { if } p_{A}<p_{B} .\end{cases} \\
\frac{\partial W_{B}}{\partial I_{B}}= \begin{cases}\frac{\partial U_{B}}{\partial I_{B}} & \text { if } p_{A} \geq p_{B} \\
\frac{\partial U_{B}}{\partial I_{B}}+\frac{\partial}{\partial I_{B}}\left[-\frac{1}{\delta}\left[F\left(p_{A}\right)-F\left(p_{B}\right)\right]+\tilde{\theta}\left[h\left(x\left(p_{B}\right)\right)-p_{B} x\left(p_{B}\right)\right]\right] & \text { if } p_{A}<p_{B} .\end{cases}
\end{gathered}
$$

The first-order conditions are found by setting the above equations equal to zero. Note, however, that in (A42)-(A43), only $\partial U_{i} / \partial I_{i}(i=A, B)$ terms matter. Any additional term will vanish at a symmetric equilibrium.

The first-order conditions for country $A$ are then given by,

$$
\begin{aligned}
\frac{\partial U_{A}}{\partial \tau_{A}} & =\frac{\partial U_{A}}{\partial p_{A}}=-x\left(p_{A}\right)+\frac{\partial T_{A}}{\partial p_{A}}-\varphi^{\prime}(E) \frac{\partial E}{\partial p_{A}}=0, \\
\frac{\partial U_{A}}{\partial t_{A}} & =\left.\frac{\partial U_{A}}{\partial p_{A}} \frac{\partial p_{A}}{\partial t_{A}}\right|_{\tau_{A}}+\left.\frac{\partial U_{A}}{\partial t_{A}}\right|_{p_{A}} \\
& =\left.\frac{\partial U_{A}}{\partial p_{A}} \frac{\partial p_{A}}{\partial t_{A}}\right|_{\tau_{A}}+\left.\frac{\partial T_{A}}{\partial t_{A}}\right|_{p_{A}}-\left.\varphi^{\prime}(E) \frac{\partial E}{\partial t_{A}}\right|_{p_{A}}=0 .
\end{aligned}
$$

At $p_{A}=p_{B}, e_{A}=e_{B}$, one can simplify equations (A44)-(A45) by substituting from (A14)-(A15) in (A44) and from (A16)-(A17) in (A45). Same conditions hold for country $B$ and we have:

$$
\begin{aligned}
& \frac{\partial U_{i}}{\partial \tau_{i}}=x\left(p_{i}\right) \varepsilon_{i}\left\{-\left[\frac{p_{i}-C\left(e_{i}\right)}{\delta \varepsilon_{i}}+\frac{\tau_{i}}{p_{i}}\right]+\frac{e_{i}}{p_{i}}\left[C^{\prime}\left(e_{i}\right)+\varphi^{\prime}(E)\right]\right\}=0 \\
& \frac{\partial U_{i}}{\partial t_{i}}=\frac{\partial U_{i}}{\partial \tau_{i}} e_{i}+\frac{x\left(p_{i}\right)}{C^{\prime \prime}\left(e_{i}\right)}\left[C^{\prime}\left(e_{i}\right)+\varphi^{\prime}(E)\right]=0
\end{aligned}
$$

where we have substituted $\varepsilon_{i}$ for $-p_{i} x^{\prime}\left(p_{i}\right) / x^{\prime}\left(p_{i}\right)$. Substituting $\partial U_{i} / \partial \tau_{i}=0$ from (A46) into (A47) gives us equation (22). Setting $-C^{\prime}\left(e_{i}\right)=\varphi^{\prime}(E)$ in (A46) then yields (21).

\section{Variation in $\delta$, the open-economy equilibrium and proof of Proposition 4:}

To simplify the calculations, we assume here that the elasticity of demand is constant. 
Substitute the optimal value of $\tau$ from (21) in (8) and insert $-C^{\prime}\left(e_{i}\right)$ for $\varphi^{\prime}(E)$. This yields

$$
p-\frac{\delta \varepsilon\left[C(e)-C^{\prime}(e) e\right]}{p}=C(e)-\delta \varepsilon,
$$

where we have dropped the subscript $i$ for simplicity in exposition. Differentiate equations (7), (15), (22) and (A48) totally with respect to $\delta .{ }^{16}$ We have

$$
\begin{aligned}
\frac{d e}{d \delta} & =\frac{-1}{C^{\prime \prime}(e)} \frac{d t}{d \delta} \\
\frac{d p}{d \delta} & =-\frac{p}{\varepsilon e}\left[\frac{1}{2 x(p) \varphi^{\prime \prime}(E)}+\frac{1}{C^{\prime \prime}(e)}\right] \frac{d t}{d \delta} \\
\frac{d E}{d \delta} & =\frac{1}{\varphi^{\prime \prime}(E)} \frac{d t}{d \delta}
\end{aligned}
$$

with

$$
\frac{d t}{d \delta}=\frac{-\frac{\varepsilon e \varphi^{\prime}(E)}{p+\delta \varepsilon}}{\left\{\frac{p}{\varepsilon e}+\frac{\delta\left[C(e)-C^{\prime}(e) e\right]}{e p}\right\}\left[\frac{1}{2 x(p) \varphi^{\prime \prime}(E)}+\frac{1}{C^{\prime \prime}(e)}\right]+\frac{\delta \varepsilon e}{p}-\frac{C^{\prime}(e)}{C^{\prime \prime}(e)}}<0 .
$$

The negative sign of (A52) follows from the convexity of $C(e)$ and $\varphi(E)$. Consequently, $d e / d \delta>0, d p / d \delta>0$ and $d E / d \delta<0$.

Turning to welfare, differentiate equation (13) totally with respect to $\delta$. We have

$$
\frac{d W^{S}}{d \delta}=\frac{d T}{d \delta}-x(p) \frac{d p}{d \delta}-\varphi^{\prime}(E) \frac{d E}{d \delta} .
$$

Next, differentiate $T=[p-C(e)] x(p)$ totally with respect to $\delta$, substitute the resulting expression in (A53) and simplify. We get

$$
\frac{d W^{S}}{d \delta}=-C^{\prime}(e) x(p) \frac{d e}{d \delta}+[p-C(e)] x^{\prime}(p) \frac{d p}{d \delta}-\varphi^{\prime}(E) \frac{d E}{d \delta} .
$$

Finally, substitute from (A49)-(A51) in (A54). After a bit of simplification, one arrives at

$$
\frac{d W^{S}}{d \delta}=\left[\frac{x(p) \tau}{C^{\prime \prime}(e) e}+\frac{\tau-e \varphi^{\prime}(E)}{2 e \varphi^{\prime \prime}(E)}\right] \frac{d t}{d \delta}>0 .
$$

\footnotetext{
${ }^{16}$ Details of the derivations can be obtained from the authors on request.
} 
The sign of (A55) follows from, among other things, the fact that $\tau<0$.

In the special case of a constant $\varphi^{\prime}(E)$, the relationship $t=-C^{\prime}(e)=\varphi^{\prime}(E)$ implies that $t$ and $e$ are also constant so that

$$
\frac{d e}{d \delta}=0
$$

Equation (A48) then determines $p$ as a function of $\delta$ only. Differentiating (A48) with respect to $\delta$ yields

$$
\frac{d p}{d \delta}=\frac{\frac{\varepsilon e \varphi^{\prime}(E)}{p+\delta \varepsilon}}{1+\left[C(e)-C^{\prime}(e) e\right] \delta \varepsilon / p^{2}}>0 .
$$

In turn, this implies that

$$
\frac{d E}{d \delta}=2 e x^{\prime}(p) \frac{d p}{d \delta}<0 .
$$

To determine the implication for welfare, consider equation (A54) again. Set $d e / d \delta=0$ from (A56), substitute for $d E / d \delta$ from (A58), and set $-C^{\prime}(e)=\varphi^{\prime}(E)$ from Proposition 3. We will have

$$
\frac{d W^{S}}{d \delta}=\left(\tau-e \varphi^{\prime}(E)\right) x^{\prime}(p) \frac{d p}{d \delta}>0
$$

Derivation of (24): Differentiate (23) with respect to $\hat{\tau}$, evaluate the resulting expression at $\left(t^{N}, \tau^{N}\right)$ and simplify. We get

$$
\left(\frac{\tau}{p^{2}}-\frac{1}{\delta \varepsilon}\right) \frac{d p}{d \hat{\tau}}+\left\{\frac{C^{\prime}(e)}{\delta \varepsilon}+C^{\prime \prime}(e)\left[\frac{e}{p}+\frac{1}{C^{\prime \prime}(e) e \varepsilon}\right]\right\} \frac{d e}{d \hat{\tau}}=\frac{1}{p} .
$$

Next, from differentiating $p=C(e)-C^{\prime}(e) e+\tau$, we have

$$
\frac{d p}{d \hat{\tau}}=-C^{\prime \prime}(e) e \frac{d e}{d \hat{\tau}}+1
$$

Substituting from (A61) into (A60) and simplifying yields

$$
\frac{d e^{N}(\hat{\tau})}{d \hat{\tau}}=\frac{1}{C^{\prime \prime}(e) e+\left[\frac{C^{\prime}(e)}{\delta \varepsilon}+\frac{1}{e \varepsilon}\right] /\left[\frac{1}{\delta \varepsilon}+\frac{1}{p}-\frac{\tau}{p^{2}}\right]} .
$$

Equation (24) follows immediately from (A62). 
Derivation of $\partial W^{S}\left(\tau^{N}, t^{N}\right) / \partial \tau$ and $\partial W^{S}\left(\tau^{N}, t^{N}\right) / \partial t$ : Compare equations (A33)(A34) with (A46)-(A46). This reveals that

$$
\begin{aligned}
\frac{\partial W_{i}^{S}}{\partial \tau_{i}} & =\frac{\partial U_{i}}{\partial \tau_{i}}+x\left(p_{i}\right) \varepsilon_{i}\left[\frac{p_{i}-C\left(e_{i}\right)}{\delta \varepsilon_{i}}+\frac{e_{i}}{p_{i}} \varphi^{\prime}(E)\right], \\
\frac{\partial W_{i}^{S}}{\partial t_{i}} & =\frac{\partial U_{i}}{\partial t_{i}}+e_{i} x\left(p_{i}\right) \varepsilon_{i}\left[\frac{p_{i}-C\left(e_{i}\right)}{\delta \varepsilon_{i}}+\frac{e_{i}}{p_{i}} \varphi^{\prime}(E)\right]+\frac{x\left(p_{i}\right) \varphi^{\prime}(E)}{C^{\prime \prime}\left(e_{i}\right)} .
\end{aligned}
$$

Now at $\left(\tau^{N}, t^{N}\right), \partial U_{i} / \partial \tau_{i}=\partial U_{i} / \partial t_{i}=0$. Equations (A63)-(A64) then reduce to

$$
\begin{aligned}
\frac{\partial W_{i}^{S}}{\partial \tau_{i}} & =x\left(p_{i}\right) \varepsilon_{i}\left[\frac{p_{i}-C\left(e_{i}\right)}{\delta \varepsilon_{i}}+\frac{e_{i}}{p_{i}} \varphi^{\prime}(E)\right], \\
\frac{\partial W_{i}^{S}}{\partial t_{i}} & =e_{i} x\left(p_{i}\right) \varepsilon_{i}\left[\frac{p_{i}-C\left(e_{i}\right)}{\delta \varepsilon_{i}}+\frac{e_{i}}{p_{i}} \varphi^{\prime}(E)\right]+\frac{x\left(p_{i}\right) \varphi^{\prime}(E)}{C^{\prime \prime}\left(e_{i}\right)} .
\end{aligned}
$$

Derivation of (34): Differentiate (33) with respect to $\hat{t}$, evaluate the resulting expression at $\left(t^{N}, \tau^{N}\right)$ and simplify. We get

$$
\left(\frac{\tau}{p^{2}}-\frac{1}{\delta \varepsilon}\right) \frac{d p}{d \hat{t}}-\frac{1}{p} \frac{d \tau}{d \hat{t}}=\frac{e}{p}+\frac{C^{\prime}(e)}{\delta \varepsilon C^{\prime \prime}(e)} .
$$

Substituting $e+d \tau / d t$ for $d p / d t$ in above and simplifying yields (34). 


\section{References}

Cremer, H. and F. Gahvari (2000) "Tax evasion, fiscal competition and economic integration," European Economic Review, 44, 1633-1657.

Cremer, H., and F. Gahvari (2001) "Second-best taxation of emissions and polluting goods," Journal of Public Economics, 80, 169-197.

Cremer, H. and F. Gahvari (2002) "Which border taxes? Origin taxes, destination taxes and the Pigouvian rule," mimeo.

Cremer, H., V. Fourgeaud, M. Leite Monteiro, M. Marchand and P. Pestieau (1996) "Mobility and redistribution: A survey of the literature," Public Finance, 51, 325-352.

Cremer, H. and P. Pestieau (2002) "Mobility and redistribution: A survey," mimeo, University of Toulouse.

Edwards, J. and M. Keen (1996) "Tax competition and the Leviathan," European Economic Review, 40, 113-134.

Haufler, A. (2001) Taxation in a Global Economy. Cambridge: Cambridge University Press.

Kanbur, R. and M. Keen (1993) "Jeux sans frontières: Tax competition and tax coordination when countries differ in size," American Economic Review, 83, 877-892.

Keen, M.J. (1989) "Pareto-improving indirect tax harmonisation," European Economic Review, 33, 1-12.

Sinn, H.W. (1994) "How much Europe? subsidiarity, centralization and fiscal competition," Scottish Journal of Political Economy, 41, 85-107.

Wellisch, D. (2000) Theory of Public Finance in a Federal State. Cambridge: Cambridge University Press.

Wilson, J. (1999) "Theories of tax competition," National Tax Journal, 52, 269-304. 